\title{
Detection rates of waterborne protozoa in water sources from Fayoum Governorate
}

\author{
Original \\ Thabet F. Sakran¹, Gamal A. El-Shahawy', Maisa A. Shalaby², Hoda Y. Sabry ${ }^{2}$, \\ Article \\ Pessant M. Matooq ${ }^{3}$, Almahy M. Elmallah ${ }^{1}$ \\ ${ }^{1}$ Department of Parasitology, Faculty of Science, Beni Swef University, Beni Swef, Egypt \\ ${ }^{2}$ Theodor Bilharz Research Institute, Imbaba, Giza, Egypt \\ ${ }^{3}$ Central Laboratory, Fayoum Drinking Water and Wastewater Company, Fayoum, Egypt
}

\begin{abstract}
Background: Waterborne protozoal infections are common health problems in many parts of the world especially in developing countries. Water is a major vehicle for transmission of protozoa such as G. lamblia, Cryptosporidium spp. as well as pathogenic and opportunistic free living amoeba (FLA).

Objective: This study aims to detect the presence of protozoal agents in tap water and storage water tanks at Fayoum Governorate, Egypt.

Material and Methods: A total of ninety five water samples were collected from different water sources, taps (65) and tanks (30), from 6 Fayoum districts. The samples were processed to detect the presence of G. lamblia cysts by Lugol's iodine stain, Cryptosporidium oocysts by modified Ziehl-Neelsen stain and FLA by cultivation. After cultivation, Acanthamoeba spp. were identified according to their morphological features and flagellation test was performed to detect amoeboflagellates.

Results: All water samples collected from tanks (100\%) were contaminated by protozoa of medical importance, while only $6(9.2 \%)$ of the tap water samples were pathogen free. The majority of water samples were contaminated with mixed protozoal infections. The overall detection rates of contaminants in water sources were 86.3\%, 52.6\%, 13.7\% by FLA, Cryptosporidium spp. and G. lamblia, respectively.

Conclusions: The recorded detection rates of waterborne protozoa present a hazard to the community resulting in silent morbidities and mortalities. It is strongly recommended to adopt proper water safety measures.
\end{abstract}

Key Words: Cryptosporidium spp., drinking water, Egypt, Fayoum governorate, free living amoebae, G. lamblia.

Received: 1 January 2017, Accepted: 8 March 2017.

Corresponding Author: Pessant M. Matooq, E-mail: pppmai@yahoo.com..

ISSN: 1687-7942, Vol. 10, No. 1 \& 2.

\section{INTRODUCTION}

From the public health point of view, a dependable supply of safe drinking water is vital for daily life. Unfortunately, the same water that promotes life can also be the bearer of dangerous contaminants in the form of protozoa that contaminate drinking water supplies in developed and developing countries. These protozoa are Giardia lamblia, Cryptosporidium spp., pathogenic and opportunistic free living amoeba (FLA).

Cryptosporidium spp. and G. lamblia are major waterborne pathogens ${ }^{[1]}$, transmitted as a result of water contamination with animal and human feces $^{[2]}$. Cryptosporidiosis is a major cause of acute diarrhea in children and chronic persistent diarrhea in HIV infected individuals with low CD4 counts ${ }^{[3]}$. G. lamblia causes large numbers of gastrointestinal infections worldwide with complications that include steatorrhea, malabsorption and growth retardation in children ${ }^{[4,5]}$. Pathogenic and opportunistic FLA are aerobic eukaryotic protists that can potentially cause infections in humans and animals ${ }^{[6]}$. In addition, Acanthamoeba spp. is known to produce chronic granulomatous amoebic encephalitis ${ }^{[7]}$ as well as corneal keratitis $^{[8]}$.

Diligent determination of dispersed waterborne protozoa in water sources is of fundamental importance, especially sources exposed to pollutants such as sewage, industrial discharge and human activities that are rarely subjected to minimal treatment before discharge into the Nile River. Possible reasons for constant contamination include inefficient coagulation, filtration and poor disinfection (e.g. no free-residual disinfectant and short contact times) during water treatment. Pathogenic microorganisms that evade treatment may survive and enter the piped distribution system and be the source of an important level of endemic disease in the population ${ }^{[9.10]}$. Therefore, the selection of suitable processes of treatment to remove this contamination is very important for safe water supply.

The safety of water is threatened by the use of old metal water distribution pipes which are more prone to develop 
biofilms on their walls, nearness of the water distribution system to the sewage system and the use of water pumps to raise pressure of water in many houses induces vacuum that draws sewage water from broken water pipe system. These factors increase the percentage of protozoa in drinking water ${ }^{[11]}$. In many countries including Egypt, the populations consume water from water storage roof tanks. The water quality changes according to the storage time, condition and cleaning of those tanks. Tanks may be contaminated from a variety of sources including piping, tank construction materials, sealed tank covers or breathing outlets improperly designed, insects, animal and bird feces that might gain access to the tanks, which leads to increase in the microbial contamination ${ }^{[12]}$.

The present study aims at detecting the presence of medically important protozoa in tap and water tanks at Fayoum Governorate, Egypt.

\section{MATERIALS AND METHODS}

This descriptive analytical study was conducted during the period from May, 2015 to October, 2015 as a part of a M.Sc. fulfillment. The samples were processed at the Central Microbiology/Parasitology laboratory of Fayoum drinking water and sanitation company.

Study area: Water samples were collected from Fayoum governorate. This governorate is bound from the east, west and north by Giza governorate, while its southern boundary is Beni Suef governorate. Samples were collected from 6 districts at Fayoum governorate (Fayoum, Sennuris, Tamia, Yousif El-Sedek, Ibshawai, Itsa) (Figure 1); and both water tap and water tanks were collected.

Sample collection, transportation and storage: Ninety five water samples were collected in $1 \mathrm{~L}$ and $2 \mathrm{~L}$ sterile polypropylene containers. The $1 \mathrm{~L}$ samples were used for detection of free living amoeba and the 2 L samples were used for screening of Cryptosporidium

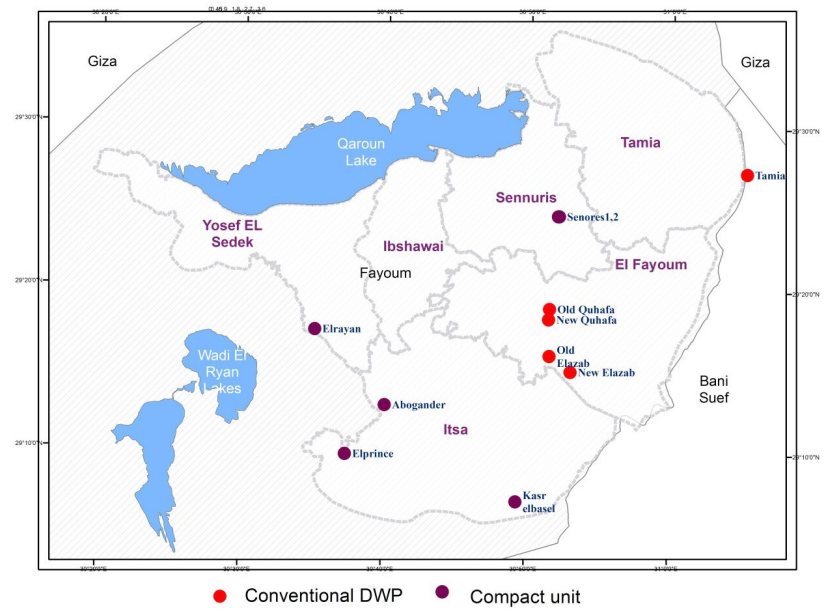

Fig. 1: Detailed main water treatment plants (WTPs) map for the studied area.

DWP: Dwelling water pump. spp. and G. lamblia. The samples were collected from households, schools and mosques. Samples were transmitted immediately using an ice box for sample preservation, to the Central Microbiology/Parasitology Laboratory of Fayoum drinking water and sanitation company, for analysis. The samples were refrigerated at $4^{\circ} \mathrm{C}$ until processed within $24 \mathrm{~h}$.

\section{Laboratory methods}

Lugol's iodine stain technique for detection of G. lamblia cyst: Lugol's iodine stains the nuclear structures of Giardia cysts maximizing recovery of cysts. Each water sample was concentrated by centrifugation at $5000 \times \mathrm{g}$ for $20 \mathrm{~min}$. The supernatant was poured off leaving the sediment which was stained with Lugol's iodine ${ }^{[13]}$. Direct smears were examined under the light microscope using 10 and 40 objective lenses to identify $G$. lamblia cysts

Modified Ziehl-Neelsen (MZN) staining for detection of Cryptosporidium oocysts: To maximize recovery of oocysts, the samples were centrifuged at $5000 \times \mathrm{g}$ for $20 \mathrm{~min}$ to concentrate the oocysts. MZN technique stains oocysts red against a blue background. Samples were screened by $40 \mathrm{X}$ and confirmed by $100 \mathrm{X}$ objectives ${ }^{[14]}$.

Cultivation and identification of FLA: Collected water samples were separately concentrated using the membrane filtration technique. One liter of each water sample was filtered through a nitro-cellulose membrane filter $(0.45 \mu \mathrm{m}$ pore size and $47 \mathrm{~mm}$ in diameter $)$ that was then removed before complete dryness. Each membrane was inverted on the surface of a non-nutrient agar plate lined with Escherichia coli and incubated at $35^{\circ} \mathrm{C}^{[15]}$. The plates were observed daily for 14 days using an inverted microscope to detect sluggishly moving trophozoites with hyaline pseudopodium protrusions, or double walled cysts with polygonal shaped interior or parallel inner and outer walls. Flagellation test was carried out using distilled water to detect amoeboflagellates (FLA other than Acanthamoeba spp.) ${ }^{[16]}$. Identification was based on the morphological characteristics of trophic, temporary flagellate and cyst stages ${ }^{[17,18]}$.

Ethical consideration: Approval to conduct this study was obtained from Fayoum drinking water and sanitation company. Permission of households and authorities in schools and mosques was obtained for collection of water samples, after explaining the aim of the study.

\section{RESULTS}

The overall detection rates in both water sources (Table 1) collected from 6 districts in Fayoum governorate were $72.7 \%, 53.7 \%, 52.6 \%, 13.7 \%$ for Acanthamoeba spp., 
FLA other than Acanthamoeba spp., Cryptosporidium spp. and G. lamblia, respectively (Figure 2).

All water samples were contaminated with medically important protozoa except for seven tap water samples that were pathogen free (Table 2). Most tap and tank water samples proved to be contaminated with more than one parasite; $42 / 65$ samples $(64.6 \%)$ and $23 / 30$ samples $(76.7 \%)$, respectively. The most common single contamination was with Acanthamoeba spp. detected in 8 tap water and 5 tank samples. The most common associations in double contamination were with Acanthamoeba spp. and amoeboflagellates (10 tap water and 6 tank samples) and Cryptosporidium spp. (8 tap water and 3 tank samples). The most common association in triple infection was between Acanthamoeba spp., Cryptosporidium spp. and amoeboflagellates which were detected in 11 tap water and 9 tank samples. Only one tank water sample was found to be contaminated by all the mentioned protozoa (Table 2). The distribution of FLA in water tanks varied. Acanthamoeba spp. alone contaminated $40 \%$ of the collected samples, amoeboflagellates were found in $6.7 \%$ and both types of FLA were found in $53.3 \%$. From tap water, Acanthamoeba spp. alone contaminated $29.2 \%$ of samples, while amoeboflagellates were found in $12.3 \%$ and both FLA were found in $38.5 \%$ (Figure 3 ).

Table 1: Detection rates of waterborne protozoa in water sources from 6 districts of Fayoum Governorate.

\begin{tabular}{|c|c|c|c|c|c|c|}
\hline & \multicolumn{2}{|c|}{ Tap } & \multicolumn{2}{|c|}{ Tank } & \multicolumn{2}{|c|}{ Total } \\
\hline & No. & $\%$ & No. & $\%$ & No. & $\%$ \\
\hline Free living amoeba (FLA) & 52 & 80 & 30 & 100 & 82 & 86.3 \\
\hline Acanthamoeba spp. & 44 & 67.7 & 28 & 93.3 & 72 & 72.7 \\
\hline Amoeboflagellates & 33 & 50.8 & 18 & 60 & 51 & 53.7 \\
\hline Cryptosporidium spp. & 34 & 52.3 & 16 & 53.3 & 50 & 52.6 \\
\hline G. lamblia & 8 & 12.3 & 5 & 16.7 & 13 & 13.7 \\
\hline
\end{tabular}
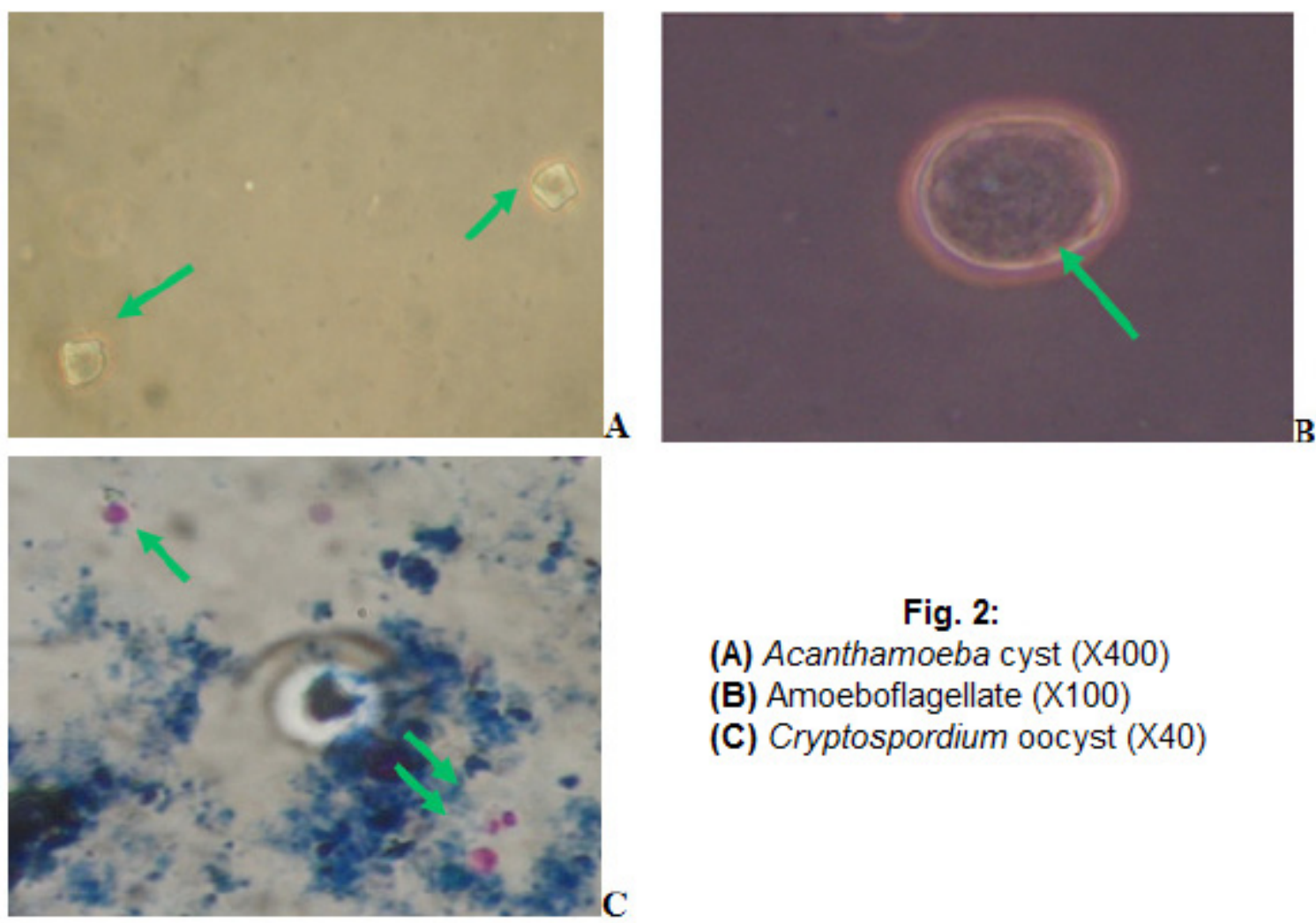

Fig. 2:

(A) Acanthamoeba cyst (X400)

(B) Amoeboflagellate (X100)

(C) Cryptospordium oocyst (X40) 
Table 2: Distribution of contaminated water sources from 6 districts of Fayoum Governorate.

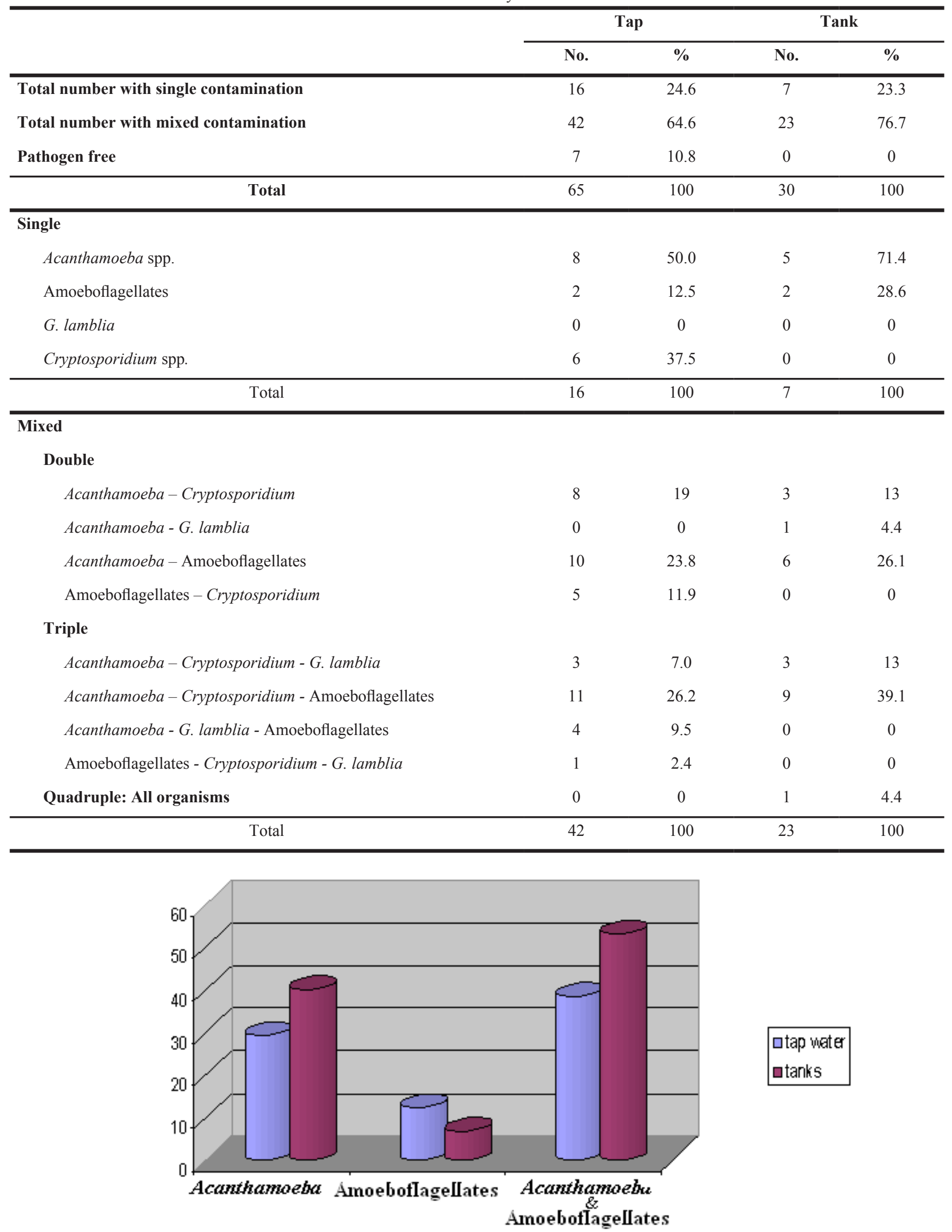

Fig. 3. Distribution of free living amoeba in drinking water samples collected from tap water and water tanks, respectively. 


\section{DISCUSSION}

One of the most important problems that the majority of the world's population is facing is the shortage of safe water for consumption. This problem is a challenge in poor developing countries as it causes serious health problems. In addition, contamination of drinking water sources with protozoan pathogens threatens millions of people in developed countries and results in severe morbidities and mortalities ${ }^{[2]}$. The problem is particularly evident in rural Egyptian villages, where the main source of water is the Nile river that is affected by many polluting activities such as sewage, industrial discharge as well as human activities. In some areas of Egypt, sewage and industrial discharge may be subjected to minimal treatment and discharged directly into the Nile river and its lakes, and canals. Higher levels of pathogens in surface water supplies, including density and variety, are expected in areas where treatment of sewage and industrial discharges is marginal or nonexistent ${ }^{[19]}$. Meanwhile, adequate and fully operational conventional drinking water treatment processes (coagulation, sedimentation, filtration, and disinfection) share in the reduction of microbial contaminants of public health concern in raw source water ${ }^{[20]}$. Effective coagulation and filtration process in water plants are important components of the conventional treatment process that control the passage of waterborne protozoan cysts/oocysts to the distribution system ${ }^{[21]}$. Therefore, determination of how much our water sources are contaminated with waterborne protozoa is of prime importance.

In the present work, 95 drinking water samples collected from Fayoum governorate were examined for potential protozoal contamination. The most frequent parasitic contamination was FLA with $86.3 \%$ overall detection rate, and $80 \%$ and $100 \%$ contamination of tap water and water tanks. Several studies were conducted in Egypt and recorded FLA in tap water with lower occurrence rates; 4\% in samples collected from different Egyptian governorates $^{[22]}, 41.7 \%$ in Gharbeya governorate $^{[23]}$ and $60.4 \%$ in Giza governorate ${ }^{[24]}$. On the other hand, similar result $(88.9 \%)$ was obtained in Qalyubia governorate $^{[23]}$. In other countries, a low detection rate $(9.3 \%)$ was recoded in $\mathrm{USA}^{[25]}$, whereas variable rates were reported in several studies all over the world; $46.9 \%$ in Korea $^{[26]}, 23 \%$ in Nicaragua ${ }^{[27]}, 22.79 \%$ in Brazil ${ }^{[28]}, 29.4 \%$ and $22 \%$ in Turkey ${ }^{[29,30]}$. However, similar results were obtained on examination of household tap water samples in UK $(89 \%)^{[31]}$ and in Ohio, USA $(79 \%)^{[25]}$. Conflicting results on FLAs contamination in tap water from different countries might be attributed to factors known to influence their presence, such as water source, water treatment method, geographic location, and differences in water temperature $^{[25]}$. High contamination of tap water with FLAs might lead to more biofilm formation along the piped water network. This is consistent with findings from a study that showed settlement of microorganisms on the inner surfaces of water pipes that would later become a source of secondary microbial contamination ${ }^{[32]}$. Therefore, high contamination of the piped water network with FLAs would definitely result in nosocomial infections due to the survival and persistence of these pathogens in the biofilms inside the storage tanks of hospitals. It was reported that FLAs are known to thrive in areas containing high bacterial content that provides them with nutrition ${ }^{[7]}$, a conclusion that is consistent with our results in detection of FLAs in all samples collected from water tanks. It was also reported that most FLAs are known to facilitate intracellular multiplication of Legionella pneumophila, Vibrio cholerae, Bacillus anthracis and Mycobacterium tuberculosis which are responsible for legionellosis, cholera, anthrax and tuberculosis, respectively ${ }^{[7]}$. On the other hand, different FLA genera infect human via sniffing of contaminated water, and they are transmitted to man causing diseases through washing before praying (ablution).

It is well known that FLA is a broad term encompassing a variety of agents including both pathogenic and nonpathogenic organisms, and the common pathogenic agents include Acanthamoeba, Naegleria, Balamuthia and Sappinia. In the present study, it was shown that the detected FLAs belonged to either Acanthamoeba spp. or other unknown amoeboflagellates based on the microscopic morphological features and flagellation test. Our results showed that Acanthamoeba spp. were the most prevalent FLA as detected in $93.3 \%$ and $67.7 \%$ of water tanks and tap drinking water samples. Other workers in Egypt recorded Acanthamoeba spp. in $41.7 \%$ and $88.9 \%$ in tap water in Gharbeya and Qalyubia governorates, respectively ${ }^{[23]}$. Lower rates were recorded in a Nicaraguan study $(21 \%, 19 \%$ and $29 \%)$ of all their water sources, tap water and water tanks, respectively ${ }^{[27]}$. Furthermore, low detection rates $(26.8 \%, 5.3 \%$ and $9.1 \%)$ were recorded in tap water in United Kingdom, Turkey and Philippines, respectively ${ }^{[30,31,33]}$. It was reported that Acanthamoeba spp. are more resistant to harsh conditions and can survive for a long time ${ }^{[34,35]}$. However, the variability of detection rates in several reports is due to variable seasonal temperature which affects the intensity and variety of Acanthamoeba spp. ${ }^{[36]}$. Our high detection rate was attributed to the time of study as the samples were collected from May to October, 2015, and most of Acanthamoeba spp. prevail during summer months ${ }^{[37]}$. Another explanation for the high detection rate of Acanthamoeba spp. is that our water samples may be rich in total dissolved solids which provide nutrition and support growth of Acanthamoeba spp. ${ }^{[38,39]}$. Beside its medical importance for causing chronic granulomatous amoebic encephalitis and corneal keratitis, Acanthamoeba spp. can harbor echo-virus ${ }^{[6]}$, and mimivirus which were discovered in $A$. polyphaga ${ }^{[40]}$.

Amoeboflagellates were found in $53.7 \%$ in all water sources and in $50.8 \%$ and $60 \%$ of tap water and water tank samples, respectively. The lower detection rates of amoeboflagellates in comparison to Acanthamoeba spp. in the present study may be due to their domestic distribution 
instead of different habitat conditions (air, water, soil) for the latter ${ }^{[37,41]}$. Low detection rates were recorded in Nicaragua $(9 \%, 4 \%$ and $5 \%)$, respectively ${ }^{[2]}$.

The detection rate of Cryptosporidium oocysts in all water sources was $52.6 \%, 52.3 \%$ in tap water, and $53.3 \%$ in water tanks. For tap water samples, lower detection rates were recorded in Egypt; $3.1 \%$ in Dakhahlia governorate ${ }^{[42]}$, and $13 \%$ in Gharbeya governorate ${ }^{[43]}$. However, the detection rate reaches $25 \%$ in Brazil ${ }^{[44]}, 34.6 \%$ in $\operatorname{Iran}^{[45]}$ and $41.6 \%$ in Baghdad $^{[46]}$. Similar results were obtained in El-Minia governorate where the investigators collected $10 \mathrm{ml}$ of water from different water sources (canals, tanks, and tap water) and they detected Cryptosporidium oocysts in $53 \%$ of their water samples ${ }^{[19]}$. High detection rate $(92 \%)$ was recorded on examining drinking water sources in Argentina and the investigators found Cryptosporidium oocysts in a concentration ranging from 20-539 oocysts/100 liter $^{[47]}$. By PCR, Cryptosporidium oocysts were detected in all examined water sources $(100 \%)$ in $\mathrm{UK}^{[48]}$, in $3.1 \%$ of tap water samples in Ismailia ${ }^{[49]}$, in $10.2 \%$ and $40.1 \%$ in samples collected from treated drinking water in Portugal $^{[50]}$ and $\mathrm{Spain}^{[51]}$, respectively. In the Spanish study, the investigators used immunofluorescent assay (IFA), and a similar result was obtained $(40.9 \%)$. As regards water tanks, Cryptosporidium oocysts were detected in $3 \%$ in Dakahlia governorate ${ }^{[52]}$. In Jordan, the investigators reported detection of Cryptosporidium oocysts in water sediment of home storage tanks of patients with diarrhea ${ }^{[53]}$. In Seoul, Republic of Korea, a waterborne outbreak of cryptosporidiosis occurred in an apartment complex, and tap water samples were collected and examined. It was found that the main drinking water source was polluted with sewage from a septic tank in the apartment complex ${ }^{[54]}$. On the other hand, the investigators detected Cryptosporidium oocysts in all water tanks $(100 \%)$ in Alexandria city, Egypt using flow cytometry ${ }^{[55]}$. Another research was conducted also in Alexandria to study cryptosporidiosis among children in urban and rural areas. The investigators collected 30 stored water samples from each area and Cryptosporidium oocysts were found in only 2 samples (6.7\%) in urban area and 4 samples (13.3\%) in the rural area ${ }^{[56]}$. Abundance of Cryptosporidium oocyst in the present work may be greatly affected by zoonotic contamination as most tanks were opened making them more liable to rodent feces shown to be reservoir host for Cryptosporidium spp. ${ }^{[57,58]}$.

The results of the present study showed that Giardia cysts were detected in $13.7 \%$ of all water samples, $12.3 \%$ from tap water and $16.7 \%$ from water tanks. In Egypt, Giardia cysts were detected in different sources of potable water samples with a lower rate $(2.1 \%)$ in Dakahlia governorate ${ }^{[52]}$ and $7.4 \%$ in tap water samples in Gharbiya governorate $^{[43]}$. Higher detection rates were reported on examination of different water sources in Argentina $(31 \%)^{[47]}$ and $41.7 \%$ in Brazil ${ }^{[44]}$, while a similar result
(15.4\%) was recorded in Iran [45]. In a study conducted in Addis Ababa, Ethiopia, the investigators reported a low detection rate in tap water $(1 \%)$ and a higher rate $(29 \%)$ in treated water storage tanks ${ }^{[59]}$. Using other methods for detection of Giardia cysts, the investigators employed flow cytometry to identify and evaluate Giardia cysts viability in water samples in Assuit and recorded 29.2\% detection rate ${ }^{[60]}$. Use of PCR allowed investigators to detect and genotype $8.4 \%$ of Giardia in Portuga ${ }^{[59]}$ and $33.8 \%$ in Spain $^{[51]}$. Using IFA, detection rates of $9.6 \%$ and $45.6 \%$ were reported in Russia ${ }^{[61]}$ and Spain ${ }^{[51]}$, respectively. In the Russian study, the investigators attributed the lower detection rate to the low sensitivity of the immunofluorescent staining methods used. It is worthwhile to add that $7.2 \%$ of the examined water samples were contaminated by both Cryptosporidium oocysts and Giardia cysts, using $\mathrm{PCR}^{[50]}$

Our study had two important limitations; first, we didn't examine the water sources for other pathogenic protozoa (Entamoeba spp.), as well as emerging protozoa such as Blastocystis spp., Cyclospora cayetanensis, Dientamoeba fragilis and Isospora belli. Second is the inability to conduct molecular techniques (PCR) to identify Naegleria spp. However, it was concluded that $89.2 \%$ of all our water sources in Fayoum governorate possess a high risk to our community. Therefore, the application of adequate operational practices combined with the promotion of source water protection programs will ensure the effectiveness of current conventional treatment processes in preventing protozoan cysts/oocysts, FLA and other microbial contaminants from entering the final water supply, thus ensuring the continuous provision of safe drinking water to consumers.

Author contribution: TF Sakran and GA El-Shahawy initiated the research idea. MA Shalaby and HY Sabry designed the study. PM Matooq collected the samples, did the parasitological examination, analyzed the data, collected the references and wrote the manuscript. AM Elmallah shared in practical work. All authors revised and approved the final version submitted for publication.

\section{CONFLICT OF INTEREST}

There are no conflicts of interest.

\section{REFERENCES}

1. Mons C, Dumètre A, Gosselin S, Galliot C, Moulin L. Monitoring of Cryptosporidium and Giardia river contamination in Paris area. Water Res, 2009; 43(1): 211-217.

2. World Health Organization. WHO guidelines for drinking-water quality. Microbial Aspects. $4^{\text {th }}$ edition, WHO Library Cataloguing-in-Publication Data, Geneva, 2011. 
3. Hunter PR, Nichols G. Epidemiology and clinical features of Cryptosporidium infection in immunocompromised patients. Clin Microbiol Rev, 2002; 15(1): 145-154.

4. Gillon J, Al Thamery D, Ferguson A. Features of small intestinal pathology (epithelial cell kinetics, intraepithelial lymphocytes, disaccharidases) in a primary Giardia muris infection. Gut, 1982; 23: 498-506.

5. Corsi A, Nucci C, Knafelz D, Bulgarini D, Di Iorio, Polito A et al. Ocular changes associated with Giardia lamblia infection in children. Br J Ophthalmol, 1998; 82: $59-62$

6. Schuster FL, Visvesvara GS. Opportunistic amoebae: challenges in prophylaxis and treatment. Drug Resist Updat 2004; 7(1): 41-51.

7. Saeed A. Acanthamoeba castellanii as a host and model to study bacterial virulence. Thesis, Division of Clinical Microbiology, Department of Laboratory Medicine, Karolinska Institutet, Stockholm, Sweden, 2009.

8. Lorenzo-Morales J, Martín-Navarro CM, LópezArencibia A, Arnalich-Montiel F, Piñero JE, Valladares B. Acanthamoeba keratitis: an emerging disease gathering importance worldwide. Trends Parasitol, 2013; 29(4): 181-187.

9. Payment P, Richardson L, Siemiatycki J, Dewar M, Edwards M, Franco E. A randomized trial to evaluate the risks of gastrointestinal disease due to consumption of drinking water meeting current microbiological standards. Am. J. Publ Hlth, 1991; 81: 703-708.

10. Payment P, Siemiatycki J, Richardson L, Gilles R, Franco E, Prevot M. A prospective epidemiological study of gastrointestinal health effects due to the consumption of drinking water. Int J Environ Hlth Res, 1997; 7: 5-31.

11. Momba MNB, Kfir R, Venter SN, Cloete TE. An overview of biofilm formation in distribution systems and its impact on the deterioration of water quality. Water SA, 2000; 26(1): 59-66.

12. Jiang DDS, Tsai YC, Tsai MC, Hsu MM, Lin YL, Chung LC et al. Investigation of a collective diarrhea outbreak among cadets of a certain training unit located in Neipu Township, Pingtung county. Epidemiology Bulletin, 2006; 22(6): 269-280

13. Garcia LS. Practical guide to diagnostic Parasitology. Second edition, ASM Press, Portland, 2009.
14. Gideon AA, Njiné T, Nola M, Menbohan SF, Ndayo, MW. Measuring resistant forms of two pathogenic protozoa (Giardia spp and Cryptosporidium spp) in two aquatic biotopes in Yaounde (Cameroon). Sante, (Montrouge, France) 2006; 17(3): $167-172$

15. Anisah N, Amal H, Kamel AG, Yusof S, Noraina AR, Norhayati M. Isolation of Acanthamoeba spp. from conjunctival sac of healthy individuals using swab. Trop Biomed, 2005, 22(1): 11-14.

16. Page FC (Ed.). An illustrated key to freshwater and soil amoebae. Freshwater Biological Association, Ferry House, Far Sawrey, Ambleside, England, 1976; 62-6.

17. Visvesvara S, Moura H, Schuster L. Pathogenic and opportunistic free-living amoebae: Acanthamoeba spp., Balamuthia mandrillaris, Naegleria fowleri, and Sappinia diploidea. FEMS Immunol Med Microbiol, 2007; 50(1): 1-26.

18. Bennett WM, Nespral JF, Rosson MW, McEvoy KM. Use of organs for transplantation from a donor with primary meningoencephalitis due to Naegleria fowleri. Am J Transplant, 2008; 8(6): 1334-1335

19. Khalifa RM, Ahmad AK, Abdel-Hafeez EH, Mosllem FA. Present status of protozoan pathogens causing water-borne disease in northern part of El-Minia Governorate, Egypt. J Egypt Soc Parasitol, 2014; 44: 559-66.

20. LeChevalier $\mathrm{M} \mathrm{W}, \mathrm{Au} \mathrm{K}$. Water treatment and pathogen control. In Process Efficiency in Achieving Safe Drinking Water. World Health Organization. IWA Publishing, London, UK, 2004; pp. 1-110.

21. Betancourt WQ, Rose JB. Drinking water treatment processes for removal of Cryptosporidium and Giardia. Vet. Parasitol, 2004; 126: 219-234.

22. Hamadto HH, Aufy SM, El-Hayawan IA, Saleh MH, Nagaty IM. Study of free living amoebae in Egypt. J Egypt Soc Parasitol, 1993; 23(3): 631-637.

23. Al-Herrawy A, Bahgat M, Mohammed A, Ashour A, Hikal W. Morpho-physiological and biochemical criteria of Acanthamoeba spp. isolated from the Egyptian aquatic environment. Iran J Parasitol, 2013; 8(2): 302-312.

24. Morsy GH, Al-Herrawy AZ, Elsenousy WM, Marouf MA. Prevalence of free-living amoebae in tap water and biofilm, Egypt. RJPBCS, 2016; 7(1): 752-759

25. Stockman LJ, Wright CJ, Visvesvara GS, Fields BS, Beach MJ. Prevalence of Acanthamoeba spp. 
and other free-living amoebae in household water, Ohio, USA (1990-1992). Parasitol Res, 2011; 108(3): 621-627.

26. Jeong HJ, Yu HS. The role of domestic tap water in Acanthamoeba contamination in contact lens storage cases in Korea. Korean J Parasitol, 2005; 43: 47-50.

27. Leiva B, Clasdotter E, Linder E, Winiecka-Krusnell J. Free-living Acanthamoeba and Naegleria spp. amebae in water sources of León, Nicaragua. Rev Biol Trop, 2008; 56(2): 439-446.

28. Winck MA, Caumo K, Rott MB. Prevalence of Acanthamoeba from tap water in Rio Grande do Sul, Brazil. Curr Microbiol, 2011; 63(5): 464-469.

29. Özçelik S, Coskun K A, Yüzlü Ö, Alim A, Malatyali E. The prevalence, isolation and morphotyping of potentially pathogenic free-living amoebae from tap water and environmental water sources in Sivas. Turkiye Parazitol Derg, 2012; 36(4): 198-203

30. Coșkun K A, Özçelik S, Tutar L, Elaldı N, Tutar Y. Isolation and identification of free-living amoebae from tap water in Sivas, Turkey. Biomed Res Int 2013; 2013: 675145. DOI: 10.1155/2013/675145.

31. Kilvington S, Gray T, Dart J, Morlet N, Beeching J $\mathrm{R}$, Frazer DG, et al. Acanthamoeba keratitis: the role of domestic tap water contamination in the United Kingdom. Invest Ophthalmol Vis Sci, 2004; 45: $165-169$

32. Rozej A, Cydzik-Kwiatkowska A, Kowalska B, Kowalski D. Structure and microbial diversity of biofilms on different pipe materials of a model drinking water distribution systems. World J Microbiol Biotechnol, 2015; 31(1): 37-47.

33. Onichandran S, Kumar T, Salibay CC, Dungca, JZ, Tabo HA, Tabo N, et al. Waterborne parasites: a current status from the Philippines. Parasites Vectors, 2014; 7: 244

34. Carlesso AM, Artuso GL, Caumo K, Rott MB. Potentially pathogenic Acanthamoeba isolated from a hospital in Brazil. Curr Microbiol, 2010; 60(3): 185-190.

35. Bradbury RS, French LP, Blizzard L. Prevalence of Acanthamoeba spp. in Tasmanian intensive care clinical specimens. J Hosp Infect, 2014; 86: 178-181.

36. Marciano-Cabral F, Jamerson M, Kaneshiro ES. Freeliving amoebae, Legionella and Mycobacterium in tap water supplied by a municipal drinking water utility in the USA. J Water Health, 2010; 8(1): 71-82.
37. Kao PM, Chou MY, Tao CW, Huang WC, Hsu BM, Shen SM et al. Diversity and seasonal impact of Acanthamoeba species in a subtropical rivershed. Biomed Res Int, 2013; 7(1): 1-8.

38. Carmena D. Waterborne transmission of Cryptosporidium and Giardia: detection, surveillance and implications for public health. In Mèndez-Vilas A (Editor) Current research, technology and education topics in applied microbiology and microbial biotechnology 2010; CFormatex Research Center, Spain, 20: 3-4

39. Siddiqui R, Khan NA. Biology and pathogenesis of Acanthamoeba Review. Parasit Vectors 2012; 5 (1), 6. DOI: 10.1186/1756- 3305-5-6.

40. Suzan-Monti M, La Scola B, Barrassi L, Espinosa L, Raoult D. Ultrastructural characterization of the giant volcano-like virus factory of Acanthamoeba polyphaga Mimivirus. PLoS One 2007; 2(3): e328.

41. De Jonckheere JF. Origin and evolution of the worldwide distributed pathogenic amoeboflagellate Naegleria fowleri. Infect Genet Evol, 2011; 11(7): 1520-1528.

42. Antonios SN, Salem SA, Khalifa EA. Water pollution is a risk factor for Cryptosporidium infection in Gharbia Governorate. J Egypt Soc Parasitol, 2001; 31(3): 963-964.

43. El-Kowrany SI, El-Zamarany EA, El-Nouby KA, El-Mehy DA, Abo Ali EA, Othman AA et al. Water pollution in the Middle Nile Delta, Egypt: An environmental study. J Adv Res, 2016; 7(5): 781-794.

44. Razzolini MT, da Silva Santos TF, Bastos VK. Detection of Giardia and Cryptosporidium cysts/ oocysts in watersheds and drinking water sources in Brazil urban areas. J Water Health, 2010; 8(2): 399- 404.

45. Rafiei A, Rahdar M, Nourozi RV. Isolation and identification of parasitic protozoa in sampled water from the Southwest of Iran. Jundishapur J Health Sci, 2014; 6(4): e23462

46. Hadi AM. Isolation and identification of Cryptosporidium spp. by reverse osmosis system of tap water in Baghdad. Baghdad Sci J, 2014; 11(2): 894-899

47. Feng Y, Zhao X, Chen J, Jin W, Zhou X, Li N, et al. Occurrence, source, and human infection potential of Cryptosporidium and Giardia spp. in source and tap water in Shanghai, China. Appl. Environ. Microbiol, 2011; 77(11): 3609-3616. 
48. Nichols RAB, Campbell BM, Smith HV. Identification of Cryptosporidium spp. oocysts in United Kingdom noncarbonated natural mineral waters and drinking waters by using a modified nested PCR-restriction fragment length polymorphism assay. Appl. Environ. Microbiol, 2003; 69(7): 4183-4189

49. Rayan HZ, Eida OM, El-Hamshary EM, Ahmed SA. Detection of human Cryptosporidium species in surface water sources in Ismailia using polymerase chain reaction. PUJ, 2009; 2(2): 119-126.

50. Almeida A, Moreira MJ, Soares S, Delgado Mde L, Figueiredo J, Silva E et al. Presence of Cryptosporidium spp. and Giardia duodenalis in drinking water samples in the north of Portugal. Korean J Parasitol, 2010; 48(1): 43-48.

51. Castro-Hermida JA, González-Warleta M, Mezo M. Cryptosporidium spp. and Giardia duodenalis as pathogenic contaminants of water in Galicia, Spain: the need for safe drinking water. Int J Hyg Environ Health, 2015; 218(1): 132-138.

52. El-Shazly AM, Gabr A, Mahmoud MS, Aziz SS, Saleh WA. The use of Ziehl-Neelsen stain, enzymelinked immunosorbent assay and nested polymerase chain reaction in diagnosis of cryptosporidiosis in immuno-competent,-compromised patients. J Egypt Soc Parasitol, 2002; 32(1): 155-166.

53. Nimri LF. Cyclospora cayetanensis and other intestinal parasites associated with diarrhea in a rural area of Jordan. Int Microbiol, 2003; 6(2):131-135.

54. Cho EJ, Yang JY, Lee ES, Kim SC, Cha SY, Kim ST, et al. A waterborne outbreak and detection of Cryptosporidium oocysts in drinking water of an older high-rise apartment complex in Seoul. Korean J Parasitol, 2013; 51(4): 461-466.
55. Khalifa AM, Ibrahim IF, Said DE, Aleem EA, Nabil RA. Cryptosporidium and Giardia in water in Alexandria: detection and evaluation of viability by flow cytometry and different stains. PUJ, 2011; 4(2): $155-164$

56. Haidar SAA, Omar EA, Sherif AR, El-Sahn AA. Cryptosporidiosis among children living in rural and urban settings in Alexandria. Bull High Inst Public Health, 2006; 36: 1-18.

57. Torres J, Gracenea M, Gomez M S, Arrizabalaga A, Gonzalez-Moreno O. The occurrence of Cryptosporidium parvum and C. muris in wild rodents and insectivores in Spain. Vet Parasitol, 2000; 92(4): 253-260.

58. Perec-Matysiak A, Bunkowska-Gawlik K, Zalesny G, Hildebrand J. Small rodents as reservoirs of Cryptosporidium spp. and Giardia spp. in southwestern Poland. Ann Agric Environ Med, 2015; 22: $1-5$.

59. Atnafu T, Kassa H, Keil C, Fikrie N, Leta $\mathrm{S}$, Keil I. Presence, viability and determinants of Cryptosporidium oocysts and Giardia cysts in the Addis Ababa water supply and distribution system. Water Qual Expo Health, 2012; 4( 1): 55-65.

60. Dyab AK, Yones DA, Sayed DM, Hassan TM. Detection, enumeration and viability evaluation of Giardia cysts in water samples using flow cytometry. GARJM, 2015; 4(6): 77-86.

61. Karanis P, Sotiriadou I, Kartashev V, Kourenti C, Tsvetkova N, Stojanova K. Occurrence of Giardia and Cryptosporidium in water supplies of Russia and Bulgaria. Environ Res, 2006, 102(3): 260-271. 